\title{
Causes, occupational risk and socio-economic determinants of eye injuries: a literature review
}

\author{
Elli DO Kyriakaki ${ }^{1}$, Emmanouil K Symvoulakis ${ }^{1}$, Gregory Chlouverakis ${ }^{2}$, \\ Efstathios T Detorakis ${ }^{3}$
}

1) Department of Social Medicine, School of Medicine, University of Crete, Greece

2) Department of Social Medicine, Biostatistics Lab, School of Medicine, University of Crete, Greece

3) Department of Ophthalmology, University Hospital of Heraklion, Crete, Greece

DOI: $10.15386 / \mathrm{mpr}-1761$

Manuscript received: 05.06.2020

Received in revised form: 28.09 .2020

Accepted: 18.11.2020

Address for correspondence:

ellkiriakaki@yahoo.com

This work is licensed under a Creative Commons Attribution-NonCommercialNoDerivatives 4.0 International License

\section{Introduction}

During the last fifty years, despite much improvement in terms of prevention and management of ocular injuries in the workplace, ocular trauma still remains one of the most common causes of blindness in the world [1]. According to World Health Organization (WHO), in 1998 evidence across the most developed countries showed that there were almost 1.6 million of blind people globally, due to ocular injuries [1]. About 2.3 million people were diagnosed with bilateral low vision and almost 1.9 million persons with monocular blindness or low vision suffered due to ocular trauma [1].

According to American Optometric Association, the most common professions with increased susceptibility to ocular injury lesions included manufacturing, industry, mining, plumbing electrical, welding and maintenance working activity [2]. However, as it is expected, most of the ocular injuries could be preventable by using suitable protective eye devices 
(PED) and strict employee's compliance with the safety rules [2]. Several types of PED are available and a suitable design is based on risk type in the workplace [2]. Finally, non-usage of ocular protective devices is mostly result of unavailability in the workplace or erroneous human decision-making process [3].

Based on the Birmingham Eye Trauma Terminology (BETT), ocular trauma refers to any injury of the eyes due to mechanic wound, chemical factors or radiation and they can be classified to open-globe and closed-globe injuries [4]. Open-globe injuries are full thickness wound of the eye globe and are subdivided into lacerations (caused by sharp objects) and ruptures (caused by blunt objects). Lacerations are subdivided into perforating, penetrating injuries and intraocular foreign bodies [4]. Closed-globe injury is a partial thickness wound (lamellar laceration). It is divided into lesions caused by blunt objects of cornea or sclera tissue and partial thickness wounds caused by sharp objects [5].

Many of the ocular injuries occur in the workplace, without omitting agricultural activities, during sport events, assaults, car accidents, and domestic works. Occupational ocular injuries are defined as those exclusively occurring in the workplace [6]. Ocular injuries occur mainly in men because they are employed in high risk occupations more frequently than females and they tend to work outdoors or more aggressively [7], but an overall 'snowball' effect on personal autonomy, family regular living, productivity and demand of community services is always reported in all cases of serious ocular injuries.

The purpose of this study was to conduct a review by providing literature views on ocular trauma occurrence, with emphasis on common causes of injury, occupational risk, socio-economic features, management peculiarities and some implications on overall care approach, from prevention to treatment.

\section{Methods}

\section{Literature search}

A systematic literature search, through four search attempts in order to cover all possible term meaning equivalents was conducted to identify articles using the following English key words in MEDLINE (PubMed):

a. (("eye injuries" [MeSH Terms] OR ("eye" [All Fields] AND "injuries" [All Fields]) OR "eye injuries" [All Fields] OR ("ocular" [All Fields] AND "injury" [All Fields]) OR "ocular injury" [All Fields]) AND ("social class" [MeSH Terms] OR ("social" [All Fields] AND "class" [All Fields]) OR "social class" [All Fields] OR ("socioeconomic" [All Fields] AND "status" [All Fields]) OR "socioeconomic status" All Fields])) AND ("2009/10/21" [PDat]:"2019/10/18" [PDat] AND "humans" [MeSH Terms] AND English[lang]) AND "adult" [MeSH Terms]), b. (("eye injuries" [MeSH Terms] OR ("eye" [All Fields] AND “injuries" [All Fields]) OR "eye injuries" [All Fields] OR ("eye" [All Fields] AND "injury" [All Fields]) OR "eye injury" [All Fields]) AND ("social class" [MeSH Terms] OR ("social”" [All Fields] AND "class" [All Fields]) OR "social class" [All Fields] OR ("socioeconomic" [All Fields] AND "status" [All Fields]) OR "socioeconomic status" [All Fields])) AND ("2009/10/21" [PDat]: "2019/10/18" [PDat] AND "humans" [MeSH Terms] AND English [lang] AND "adult" [MeSH Terms]),

c. (("eye injuries" [MeSH Terms] OR ("eye" [All Fields] AND "injuries" [All Fields]) OR "eye injuries" [All Fields] OR ("ocular" [All Fields] AND "injury" [All Fields]) OR "ocular injury" [All Fields]) AND ("employment" [MeSH Terms] OR "employment" [All Fields] OR ("occupational" [All Fields] AND "status" [All Fields]) OR "occupational status" [All Fields])) AND ("2009/10/21" [PDat]: "2019/10/18” [PDat] AND "humans" [MeSH Terms] AND English [lang] AND "adult" [MeSH Terms]),

d. (("eye injuries" [MeSH Terms] OR ("eye" [All Fields] AND "injuries" [All Fields]) OR "eye injuries" [All Fields] OR ("eye" [All Fields] AND "injury" [All Fields]) OR "eye injury" [All Fields]) AND ("employment" [MeSH Terms] OR "employment" [All Fields] OR ("occupational" [All Fields] AND "status" [All Fields]) OR "occupational status" [All Fields])) AND ("2009/10/21" [PDat]: "2019/10/18" [PDat] AND "humans" [MeSH Terms] AND English [lang] AND "adult" [MeSH Terms]).

Apart from articles retrieved by the search, included in Appendix, we also looked into their reference lists and kept all the articles related to ocular trauma (references 25-32 in the Appendix).

\section{Eligibility criteria}

Two researchers (EDOK and EKS) screened the key words, the titles and the abstracts to firstly assess content compatibility. All included articles offered information on ocular trauma. There were several articles irrelevant to ocular injuries and they were excluded from this study. Articles that generally described the risk factors on patient's health of some occupational categories were also excluded. Articles dealing with ocular injuries among specific professions in relation to social aspects were also included.

\section{Data extraction and analysis}

Reported information included authorship, publication year and country of each study, publication type, sample size and response rate when available, study design, type of major ocular injury, common cause of injury and care peculiarities (Appendix). Almost all studies fulfilled the details described except from three that care peculiarities were not reported. From all the articles through reference screening, we focused on the type of major injury reported the common cause of injury and care peculiarities. 


\section{Results}

\section{Literature screening}

Systematic search of the literature retrieved 72 articles of which 17 were included in this study and were eligible for all data requirements regarding patients' characteristics, type and common cause of ocular injuries [8-24]. Overlapping publications through all search attempts made in this systematic review were isolated. Eight studies with ocular injuries were identified through reference tracking tactic and also included in the review [25-32], based on three specific variables that were analyzed: the type of major injuries, the common cause of injury and management peculiarities (Figure 1). These articles are also presented in Appendix [25-32]. The total number of articles included in this review was 25 (Figure 1).
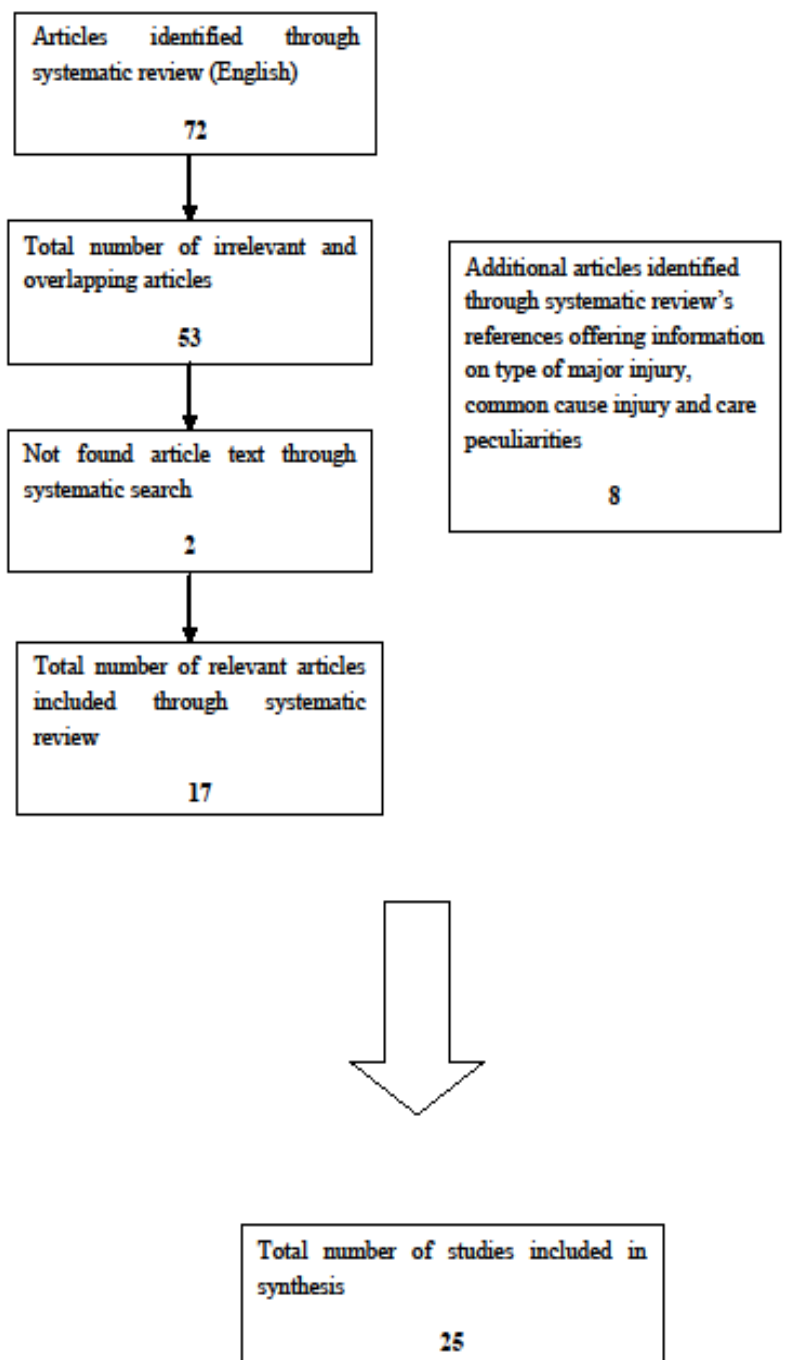

Figure 1. Systematic review flowchart (PubMed).

\section{Study characteristics and quality figures}

All articles, as shown in the Appendix, were published mostly during the last decade and were conducted in countries with different levels of development. Most of the publication types were original and study design was mainly retrospective $(n=10)$, cross-sectional $(n=6)$ and prospective $(n=4)$. Two of the studies included in the Appendix were cohort studies $[10,15]$, while a national survey to identify risk factors of eye injuries among Greek endodontists was identified [12]. One study was descriptive, relating the epidemiology of traumatic lenticular subluxation to low visual loss in Indians, caused by sports activities [9]. A pragmatic randomized trial was also included in the Appendix, investigating the most common cause of injury among quarry workers, as many Indians are employed in quarries from an early age to contribute to their family income [13]. Reported response rate of included studies was over $50 \%$.

\section{Outcome measurements}

\section{Eye injuries, causes and care services}

Studies included in the Appendix concluded that most eye injuries were work-related $[8,10-16,18,20,21$ 24,26-29]. Working environment and eye injuries is a challenging issue of literature discussion, as workplace is related with serious eye trauma. Most common types of ocular injuries are corneal foreign bodies [8,12,15,22,23,28-30], globe ruptures [24], lamellar lacerations [30], hyphema of the anterior chamber [26] and traumatic cataract $[8,13]$. It was also shown that severe work-related ocular injuries occur due to chemical burns and they cause serious eye disorders as they destroy all globe tissues, frequently leading to blindness $[11,14,16,22]$. Many eye injuries also occur during sport activities, especially in childhood (9), assaults mainly in males [25,31] and falls at home in females [25]. Highrisk occupations related to eye traumas include metal workers, welders, grinding and construction workers $[8,12,23,27-30,32]$ and workers occupied in chemical industries $[11,14,16,22]$.

Many patients have visited clinics and hospitals $[12,16,23]$, whilst others have delayed to seek medical care because of the distance between their residence and hospital [9]. In a study from USA, about $60 \%$ of the reported eye injuries were penetrating lesions and six out of 10 patients admitted to hospital in less than 6 hours [27], while a study in Australia showed that 70\% of eye injuries were due to intraocular foreign bodies and admission to hospital was registered in less than 30 minutes [28]. Moreover, patients with corneal lacerations sought for medical treatment with a delay of more than 24 hours, due to the fact that sufferers were unaware of their trauma consequences [31]. Time of recovery or hospital 
stay depends on type of eye injury. From the available information, average time of recovery among patients with chemical burns was 22 days [16] and in cases of hyphema of the anterior chamber the mean duration of hospital stay was 3-5 days [26]. Patients with chemical burns, corneal abrasions and corneal foreign bodies, being the most common sufferers, needed a follow-up within 6 days [22]. Many eye injuries registered to occur during early and late afternoon [24,31].

\section{Barriers and attitudes towards protective measures}

Most of the articles reported that eye injuries occurred in the workplace when use of protective eye devices (PED) is poor $[8,10-13,15,16,18,21,23,26$ $28,30]$. It was also suggested that some workers did not use PED due to unavailability $[8,21]$ and 'unaffordability' [21]. Another study found that there was low workers' compliance with safety regulations [23]. Furthermore, two studies found that Indian workers did not wear PED because of the climatic conditions [26] and cultural, mostly language driven, limitations [30]. It was also reported that using faulty devices does not protect $[12,22]$. Finally, most of the studies supported that educating workers and promoting protective eyewear are essential factors, if attention is paid to all safety regulations.

In detail, as shown in table I, two studies were conducted among cocoa Indian farmers and it was reported that reasons of not using PED were because they were unavailable or faulty $[8,21]$. Cocoa farmers were also of low education, with poor skills, and they were unaware of ocular trauma risks $[8,21]$. A study conducted among quarry workers assumed that the reason of not trying PED was due to non-compliance with safety work regulations [13]. Another reason was due to weather conditions (high temperature), so workers felt uncomfortable with PED [26]. Cultural determinants among workers may influence the process of decision making by using or not PED [30]. Language was a limitation among foreign workers to read and understand instructions of using PED, which means that they inevitably ignored a risky situation as not being practically informed [30]. Nationality, as independent risk determinant, does not seem to affect the reasons of not using PED as shown in table I, while educational level and lower social status appear more likely to affect the use of PED.

Table I. Barriers reported for not using PED classified by environment/occupation and nationality.

\begin{tabular}{|c|c|c|}
\hline Environment/occupation & Nationality & Barrier \\
\hline Workplace (cocoa farmers) & South African & Unavailability and unaffordability, high cost of PED equipment (8) \\
\hline Workplace (chemical workers) & Chinese & $\begin{array}{l}\text { Low educational level, luck of safety consciousness and risk } \\
\text { awareness (11) }\end{array}$ \\
\hline Workplace (endododists) & Greek & Inadequacy at the time of injury (12) \\
\hline Workplace (quarry workers) & Indian & Non-compliance with PED regulations in the workplace (13) \\
\hline $\begin{array}{l}\text { Workplace (craft, repair and precision } \\
\text { production workers) }\end{array}$ & English & Lack of need for PED (15) \\
\hline $\begin{array}{l}\text { Workplace (factory and construction } \\
\text { workers) }\end{array}$ & Chinese & PED was regarded as a routine procedure (16) \\
\hline Workplace (not reported) & Americans & Low education level in addition with improper use of PED (18) \\
\hline Workplace (cocoa farmers) & South African & $\begin{array}{l}\text { Lack of economic funds, uncomfortable, unavailability, not seeing } \\
\text { well, lack of training and ignorance }(21)\end{array}$ \\
\hline Workplace (chemical and grinding workers) & Canadian & $\begin{array}{l}\text { Inappropriate for specific tasks undertaken, failure to required } \\
\text { standards (22) }\end{array}$ \\
\hline Workplace (grinding workers) & Australian & $\begin{array}{l}\text { Poor compliance with PED use and inappropriate for the task } \\
\text { undertaken (23) }\end{array}$ \\
\hline Workplace (not reorted) & Asians & Hot weather and uncomfortable PED (26) \\
\hline Workplace (not reported) & American & The risk for performing a specific task was undertaken (27) \\
\hline Workplace (grinding workers) & Australian & $\begin{array}{l}\text { Inadequate protection while grinding. The use of PED supplies only } \\
\text { frontal or frontal-side protection (28) }\end{array}$ \\
\hline Workplace (grinding workers) & Indian & $\begin{array}{l}\text { Racial or cultural variations, inappropriate PED and not correctly } \\
\text { fitted (30) }\end{array}$ \\
\hline
\end{tabular}




\section{Discussion}

Most injuries are occupational and most sufferers are men at a productive period of their life. Nationality does not affect ocular injuries, as shown in table I. However, a study of 2008, in Singapore, showed that racial variation among workers of Indian ethnicity was identified as a barrier for not using PED [30]. Almost limited PED usage is common and reasons differ due to geographic factors, culture determinants, educational level and socio-economic status. Injuries are related to specific occupational activity, being of high risk, such as welders, farmers, metalworkers, manufacturers and grinding workers $[8,13,23,27-30,32]$. Many ocular injuries were also caused by chemical burns, which seem to be a common cause of ocular injuries $[11,14,16,22]$.

They frequently lead to complete destruction to all globe surface tissues and they cause serious global disorders. As a result, sufferers have important limitations in their daily activities [14]. In a recent study in China, it is shown that 8 out of 10 eye injuries occurred due to inappropriate chemical handling and machine functionality [11]. Moreover, workers were unaware of the risks and safety regulations due to a low educational level [11]. It is expected that educating chemical workers and their employers is essential in order to provide help at a first aid level and reduce complications. In another survey conducted to investigate ocular injuries in the workplace, it was found that workers from low socio-economic and educational level have increased risk of suffering eye injuries, being disproportionally exposed in high risk occupations [8]. Poor knowledge or information on potential eye injury consequences lead to increased risk whilst performing their duties [27]. As shown in table I, there is a variety of barriers for not using PED, and this is independent of nationality. However, it is interesting that workers coming from countries with different development level may not use PED due to difficulty to read or understand PED regulations in the workplace. It is essential for employers to actively undertake efforts to properly inform employees before they perform their duties.

Another study showed that ocular injuries occur during sport activities to younger people and they could be preventable by using PED [9]. There are many children suffering an eye injury, so it is essential to use suitable PED when participating in high risk for ocular trauma sports [9]. Proper PED design and suitable protection is another factor to be taken into consideration. In a survey conducted among Greek endododists, it was found that many eye injuries occur during performing their private practice activity and caused by amalgam particles [12]. It is noted that PED were used at the time of injury, but those were not accurately designed to offer full protection [12].

It is interesting that workers tend to change eye protection behavior after an injury [15]. As work related eye protection behavior improves, the likelihood to use
PED when performing a similar task increases due to a then better safety regulation adherence [15]. In a study focusing on socio-economic deprivation and eye trauma, researchers found that one quarter of workers who reported to be intoxicated at the time of injury suffered an ocular injury and those from deprived areas had higher risks [19]. Employers should enhance strict work regulations and alcohol should be prohibited during their working duties, possibly with randomly frequent site testing and penalties. As behavior determinants appear to be interlinked, expression of violence, in many of its forms, is likely to lead to eye traumatic events. Ocular injuries were often caused by assaults particularly in males, while in females eye traumas were caused by falls at home $[25,31]$.

In some cases, patients seek medical treatment late because of long distances between their residence and hospital, being access affected due to financial limitations as well [9], combined with unawareness about the severity of the injury and its complications [9,31]. There is a need of 'smartly' skilled doctors at local primary care units to provide help at a first aid level and perform referrals, when necessary, by facilitating access in terms of good clinical practicing. Types of work related injuries reported to be corneal foreign bodies $[8,12,15,22,23,28$ $30]$, traumatic cataract $[8,13]$, chemical burns which may cause complete destruction of the globe tissues [15,22], globe ruptures [24], hyphema of the anterior chamber [26], and lamellar lacerations [30]. It was also observed through this systematic review that traumatic cataract was the most common cause of ocular trauma in South Africa and India [8,13]. Moreover, many children suffered an eye injury while working in quarries in India, but quarry owners refused that they employ children [13]. It is worth to be mentioned that many eye injuries caused by chemical burns occurred more often a seasonal occurrence, mostly during summer and autumn than winter and spring [11]. In addition, in a study conducted in Egypt, it was described that 8 out of 10 open globe injuries, occurred between 12:00-5:59 pm [31]. It is expected that as the most common causes of injuries are violent behavior related, some mainly occur at an urban environment. Elaborating similar information, geo-temporal, lesion and cause related, details $[2,3,4,6,31,33,34]$ could be offered, to develop management algorithms, as predictive elements to facilitate proper care access.

As shown in the Appendix, average hospital stay or recovery time is related to the severity of an eye injury. Eye injuries caused by chemical burns have an average recovery period of 22 days [16]. Corneal abrasions and corneal foreign bodies need a follow-up surveillance within 6 days on average [22], hyphema of the anterior chamber, vitreous hemorrhage and corneal perforations of 3-5 day average hospital stay [26]. In Australia, it was reported that $26 \%$ of the injured patients sustained another injury in the past during domestic activities such as grinding, 
and vision loss from a previous trauma in the past was rare but possible [32]. Training initiatives, focused on first aid measures, should be introduced to deal with ocular trauma in order to not lose critical time, especially in those caused by chemical burns $[11,14,28]$ and those occurring during sport activities [9]. In a survey conducted across 21 military hospitals in China, to record ocular injuries at a wide range of occurrence, it was found that the most common listed were due to sports activities [35]. As second cause eye injuries were work-related, in armed police and army during skill training, and it was observed that military training-related eye injuries decreased when personnel were educated [35]. In a survey conducted among Nigerian metal arc welders, the major risk factor for cataract was a past eye injury episode [36]. In countries with increased rates of criminality, where the most common cause of ocular injuries are assaults caused, public opinion should be informed about the consequences of violent behaviors [31], covering issues from socio-economic deprivation effects to substance abuse. Future research is needed to be undertaken in order to provide evidence of how better eye care service design can be supported from preventative to curative actions in regards to ocular trauma. Focusing on a better overall management approach of those injuries it may be useful to discuss some 'hotspots' for prospective health planning (Box 1).

\section{Study limitations}

A possible limitation of this review is that some relevant articles may have been missed as it is often occurring when a literature search is undertaken [37]. Strict criteria may reduce the ability to expand inclusion sometimes. To minimize this eventuality, all articles were screened and checked by two researchers. Another limitation is that systematic review was based on a single but major database search and to buffer this limitation emphasis was given to all reported references of the included studies by screening them one by one. Due to the study setting and methodology variety, a major effort to offer homogeneous and compact information has been made. For this reason, information was listed in subtopics as shown in the Appendix, in order to better collect research "puzzles" of each study included and offer a more detailed 'panorama' of results section. "Minor" trauma such as corneal abrasions and corneal foreign bodies usually heal with no consequences on the visual function, as opposed to open globe injuries, ocular burns and severe closed globe injuries that may be associated with significant visual disability. For this reason, not all eye injury types equally affect sufferers' quality of life and care demand. Additionally, this review does not analyze the impact of the delayed diagnosis or treatment of patients with ocular trauma, but it focuses on determinants related to the absence or inadequacy of protection measures. This paper mostly addresses issues of occupational medicine rather than clinical information related to ocular trauma. We acknowledge that emphasis is not given on factors determining the outcome of an ocular trauma from a clinical or surgical standpoint as our search offered little information on lesion type distinction (such as the involvement of the anterior or posterior ocular segment or the presence of sight-threatening findings including central corneal lacerations, damage to the macula, the optic disc or the optic nerve). Instead, emphasis is given on the occupational and socio-economic impact of ocular trauma and the need to provide related information to employers, employees, health professionals and health care providers. Retrospective and prospective research projects are required in order to match clinical and outcome information from secondary and tertiary hospital units with better prevention and social care initiatives.

\section{Conclusions}

Occupational eye injuries can be major causes of morbidity and disability. Severe ocular wounds such as globe ruptures, corneal foreign bodies, lamellar lacerations, traumatic cataract are grouped among such lesions. Just listing the previously mentioned injuries one can think that proper eye protection is a more complex issue than it appears. Sometimes, PED were not available in the workplace, or they were faulty and not suitable for the task undertaken or the climate, not to mention ignorance, inertia, underestimation, poor education, and other parameters that could influence workers' decision-making to take cautions. It has been also emerged that most eye injuries could be preventable by using appropriate PED. Educational initiatives by offering information on types of traumas and time of recovery or risk of permanent lesion would be useful. Summarizing information from this review, it appears challenging to promote first aid level services, interlinking primary, secondary and tertiary care through flexible, effective and cost analysis driven decision algorithms, by observing geo-spatial eye care needs, in order to improve outcomes.

\section{References}

1. Négrel AD, Thylefors B. The global impact of eye injuries. Ophthalmic Epidemiol. 1998;5:143-169.

2. Almoosa A, Asal A, Atif M, Ayachit S. Occupational Eye Injury: The Neglected Role of Eye Protection. Bahrain Med Bull. 2017;39:82-84.

3. Dannenberg AL, Parver LM, Brechner RJ, Khoo L. Penetrating eye injuries in the workplace The National Eye Trauma System Registry. Arch Ophthalmol. 1992;110:843-848.

4. Mela EK, Dvorak GJ, Mantzouranis GA, Giakoumis AP, Blatsios G, Andrikopoulos GK, et al. Ocular trauma in a Greek population: review of 899 cases resulting in hospitalization. Ophthalmic Epidemiol. 2005;12:185-190.

5. Kuhn F, Morris R, Mester V, Witherspoon CD, Mann L, Maisiak R. Epidemiology and socioeconomics. Ophthalmol 
Clin North Am. 2002;15:145-151.

6. Thompson GJ, Mollan SP. Occupational eye injuries: a continuing problem. Occup Med (Lond). 2009;59:123-125.

7. Yalcin Tök O, Tok L, Eraslan E, Ozkaya D, Ornek F, Bardak Y. Prognostic factors influencing final visual acuity in open globe injuries. J Trauma. 2011;71:1794-1800.

81. Boadi-Kusi SB, Hansraj R, Kumi-Kyereme A, Mashige $\mathrm{K}$, Awusabo-Asare K, Ocansey S, et al. Ocular health assessment of cocoa farmers in a rural community in Ghana. J Agromedicine. 2014;19:171-180.

9. Khokhar S, Agrawal S, Gupta S, Gogia V, Agarwal T. Edidemiology of traumatic lenticular subluxation in India. Int Ophthalmol. 2014;34:197-204.

10. Asharlous A, Hashemi H, Yekta A, Ostadimoghaddam H, Gharaee H, Khabazkhoob M. Tear film secretion and stability in welders. Cont Lens Anterior Eye. 2018;41:426-429.

11. Ye C, Wang X, Zhang Y, Ni L, Jiang R, Liu L, et al. Tenyear epidemiology of chemical burns in western Zhejiang Province, China. Burns. 2016;42:668-674.

12. Zarra T, Lambrianidis T. Occupational ocular accidents amongst Greek endodontists: a national questionnaire survey. Int Endod J. 2013;46:710-719.

13. Adams JS, Raju R, Solomon V, Samuel P, Dutta AK, Rose $\mathrm{JS}$, et al. Increasing compliance with protective eyewear to reduce ocular injuries in stone-quarry workers in Tamil Nadu, India: a pragmatic, cluster randomized trial of a single education session versus an enhanced education package delivered over six months. Injury. 2013;44:118-125.

14. Le Q, Chen Y, Wang X, Li Y, Hong J, Xu J. Vision-related quality of life in patients with ocular chemical burns. Invest Ophthalmol Vis Sci. 2011;52:8951-8956.

15. Blackburn JL, Levitan EB, MacLennan PA, Owsley $\mathrm{C}$, McGwin $\mathrm{G}$ Jr. Changes in eye protection behavior following an occupational eye injury. Workplace Health Saf. 2012;60:393-400.

16. Le Q, Chen Y, Wang X, Hong J, Sun X, Xu J. Analysis of medical expenditure and socio-economic status in patients with ocular chemical burns in East China: a retrospective study. BMC Public Health. 2012;12:409.

17. Ghaedi G, Ghasemi H, Mousavi B, Soroush MR, Rahnama P, Jafari F, et al. Impact of psychological problems in chemical warfare survivors with severe ophthalmologic complication, a cross sectional study. Health Qual Life Outcomes. 2012;10:36.

18. Luo H, Beckles GL, Fang X, Crews JE, Saaddine JB, Zhang $\mathrm{X}$. Socioeconomic status and lifetime risk for workplace eye injury by a us population aged 50 years and over. Ophthalmic Epidemiol. 2012;19:103-110.

19. Low L, Hodson J, Morris D, Desai P, MacEwen C. Socioeconomic deprivation and serious ocular trauma in Scotland: a national prospective study. Br J Ophthalmol. 2017;101:1395-1398.

20. Chua D, Wong W, Lamoureux EL, Aung T, Saw SM, Wong TY. The prevalence and risk factors of ocular trauma: the Singapore Indian eye study. Ophthalmic Epidemiol. 2011;18:281-287.

21. Boadi-Kusi SB, Hansraj R, Mashige KP, Ilechie AA. Factors associated with protective eyewear use among cocoa farmers in Ghana. Inj Prev. 2016;22:365-369.

22. Zakrewski H, Chung H, Sanders E, Hanson C, Ford B. Evaluation of occupational ocular trauma: are we doing enough to promote eye safety in the workplace? Can J Ophthalmol. 2017;52:338-342.

23. Northey LC, Bhardwaj G, Curran S, McGirr J. Eye trauma epidemiology in regional Australia. Ophthalmic Epidemiol. 2014;21:237-246.

24. Ahmed SA, Zaki RG. Forensic analysis of ocular injuries during the 2011 revolution in Egypt. Forensic Sci Int. 2013;233:348-354.

25. Raymond S, Jenkins M, Favilla I, Rajeswaran D. Hospitaladmitted eye injury in Victoria, Australia. Clin Exp Ophthalmol. 2010;38:566-571.

26. Chang $\mathrm{CH}$, Chen $\mathrm{CL}$, Ho $\mathrm{CK}$, Lai $\mathrm{YH}, \mathrm{Hu} \mathrm{RC}$, Yen YL. Hospitalized eye injury in a large industrial city of South-Eastern Asia. Graefes Arch Clin Exp Ophthalmol. 2008;246:223-228.

27. Kanoff JM, Turalba AV, Andreoli MT, Andreoli CM. Characteristics and outcomes of work-related open globe injuries. Am J Ophthalmol. 2010;150:265-269.e2.

28. Shepherd M, Barker R, Scott D, Hocjey R, Spinks D, Pitt R. Occupational Eye Injuries. Queensland Injury Surveillance Unit; 2006.

29. McCall BP, Horwitz IB, Taylor OA. Occupational eye injury and risk reduction: Kentucky workers' compensation claim analysis 1994-2003. Inj Prev. 2009;15:176-182.

30. Ngo CS, Leo SW. Industrial accident-related ocular emergencies in a tertiary hospital in Singapore. Singapore Med J. 2008;49:280-285.

31. Soliman MM, Macky TA. Pattern of ocular trauma in Egypt. Graefes Arch Clin Exp Ophthalmol. 2008;246:205-212.

32. Raymond S, Favilla I, Nguyen A, Jenkins M, Mason G. Eye injuries in rural Victoria, Australia. Clin Exp Ophthalmol. 2009;37:698-702.

33. Hasset PD, Kelleher CC. The epidemiology of occupational penetrating eye injuries in Ireland. Occup Med (Lond). 1994;44:209-211.

34. Voon LW, See J, Wong TY. The epidemiology of ocular trauma in Singapore: perspective from the emergency service of a large tertiary hospital. Eye (Lond). 2001;15(Pt 1):75-81.

35. Qiu HY, Zhang MN, Zhang Y, Jiang CH. The survey of the causes of eye injury of various services in China. Mil Med. 2011;176:1051-1055.

36. Megbele Y, Lam KB, Sadhra S. Risks of cataract in Nigerian metal arc welders. Occup Med (Lond). 2012;62:331-336.

37. Ganann R, Ciliska D, Thomas H. Expending systematic reviews: methods and implications of rapid reviews. Implement Sci. 2010;5:56. 


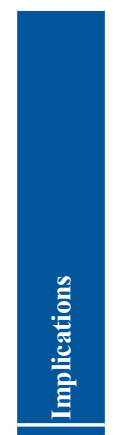

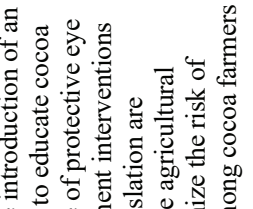

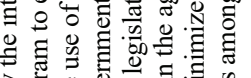

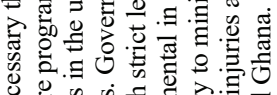

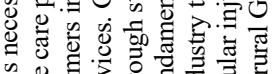

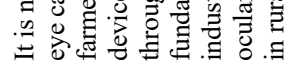

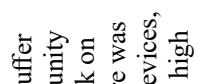

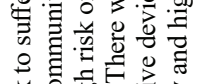

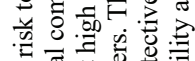

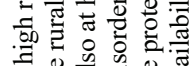

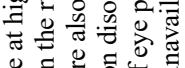

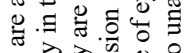

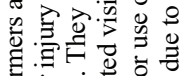

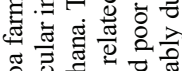

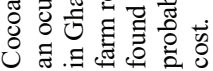

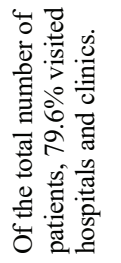

范

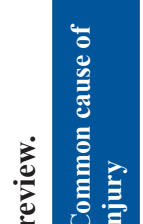

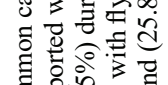

高设

它.

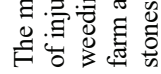

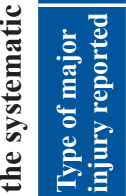

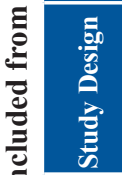

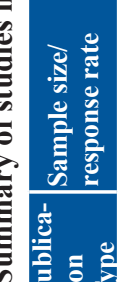

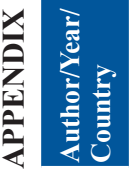
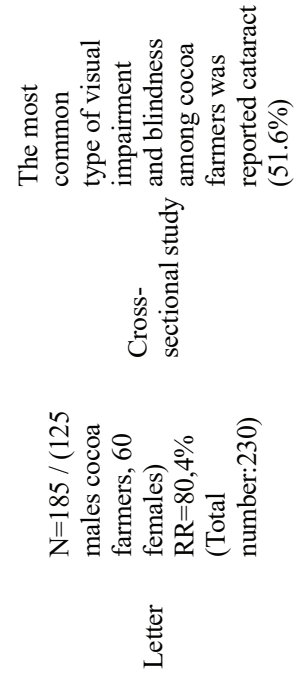

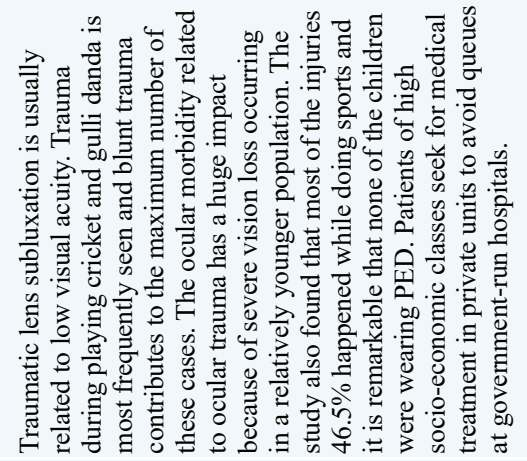

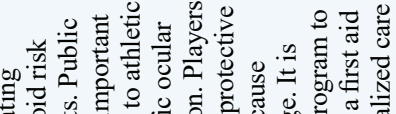

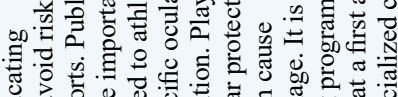

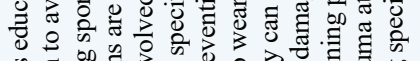

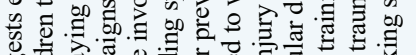

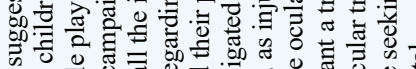

के

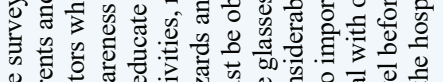

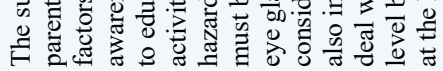

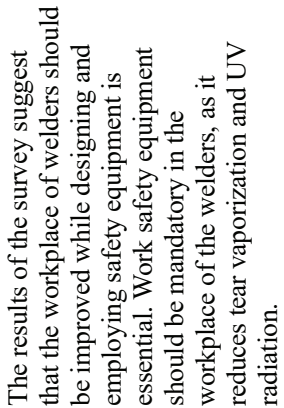

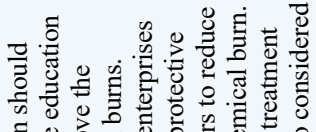

흔,

施

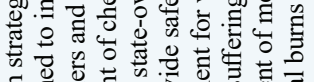

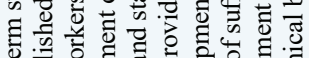

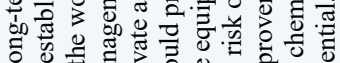

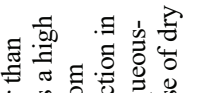

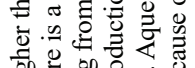

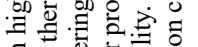

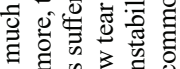

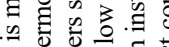

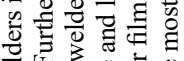

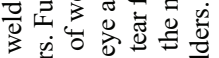

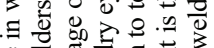

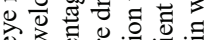

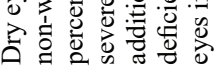

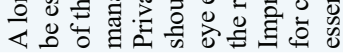
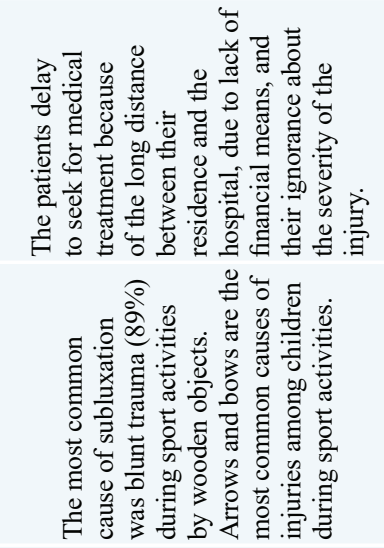

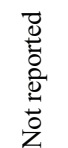

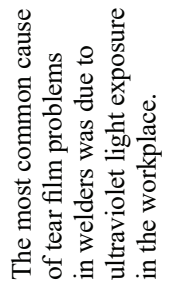

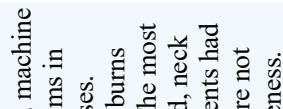

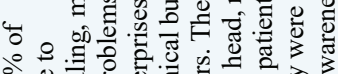

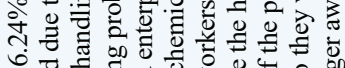

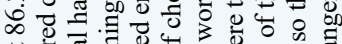

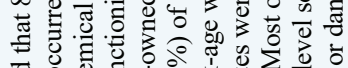

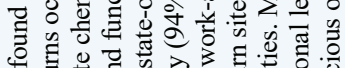

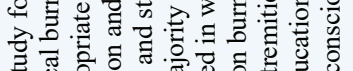

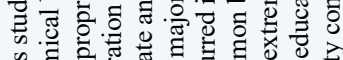

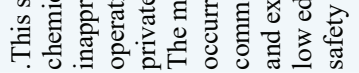

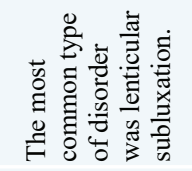

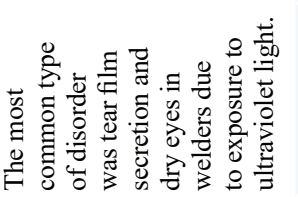

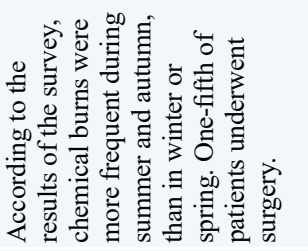




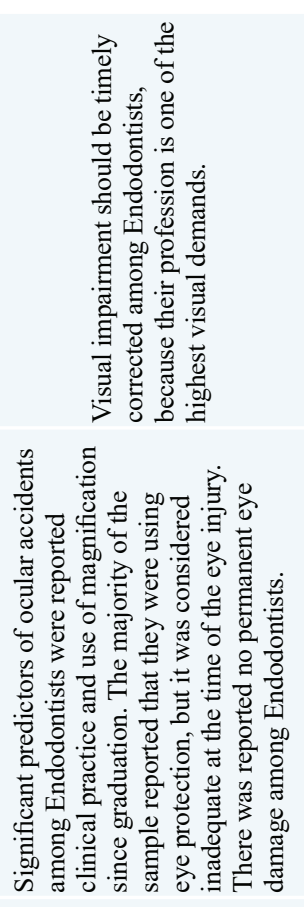

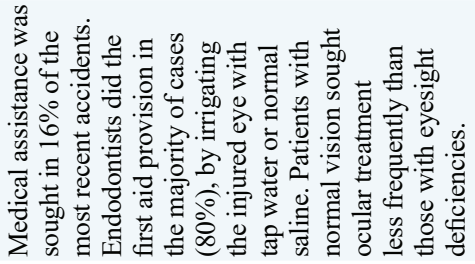
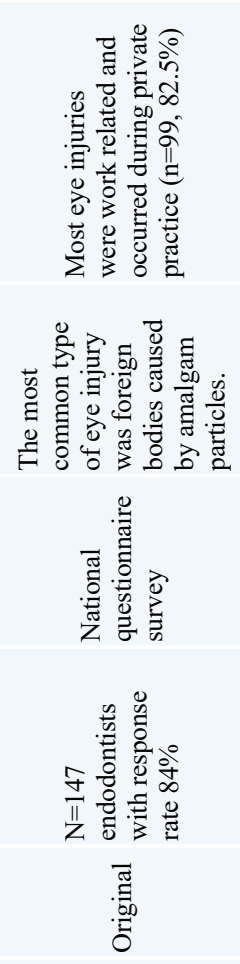

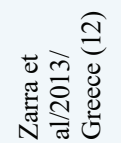
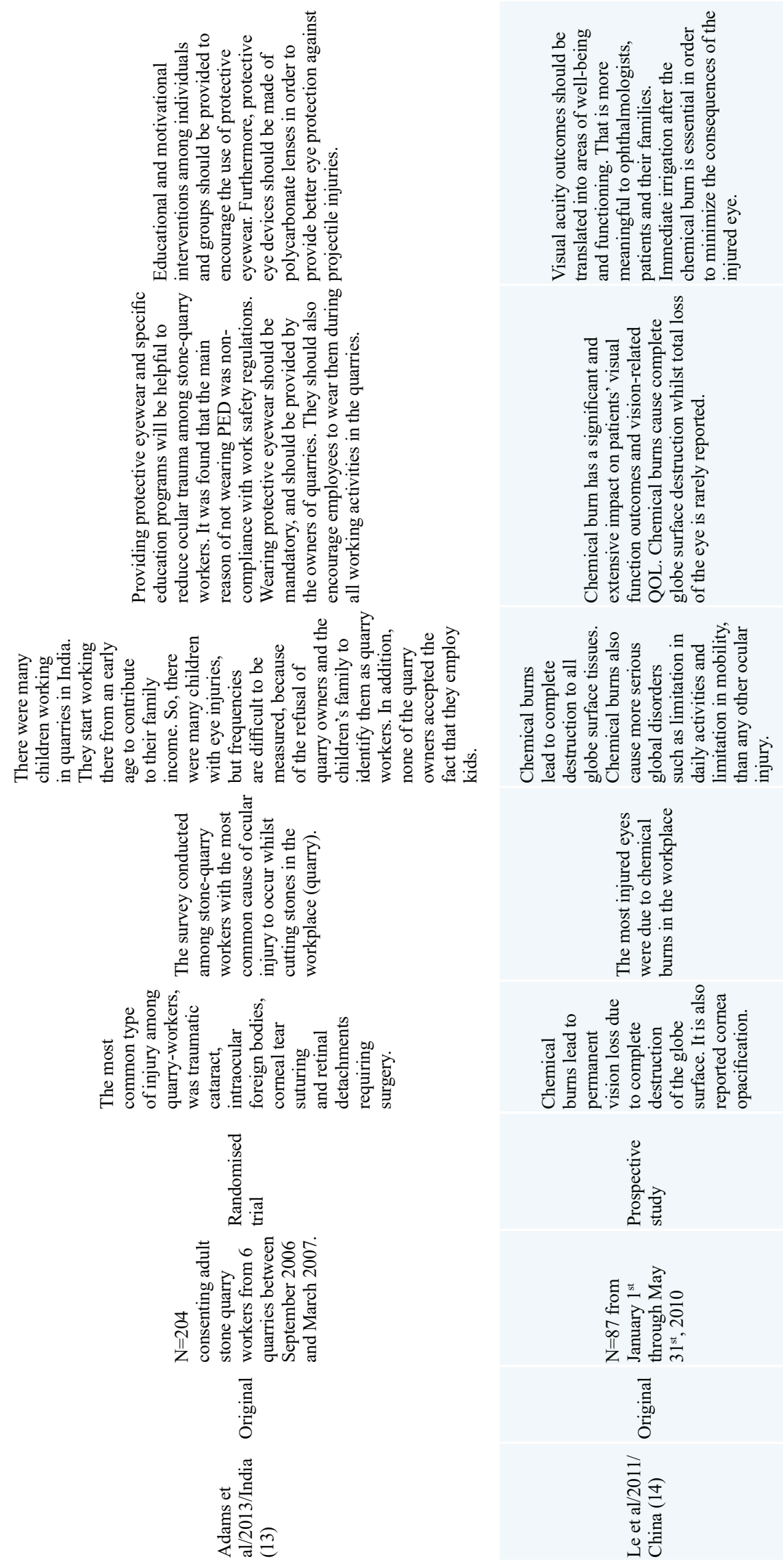

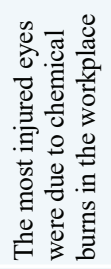

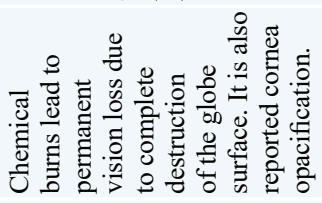
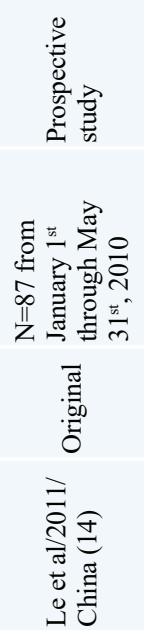


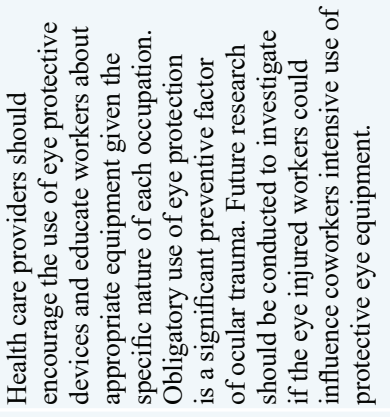

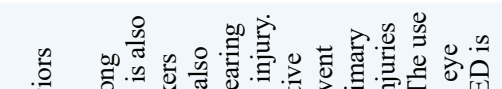

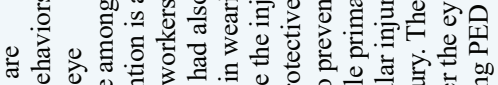

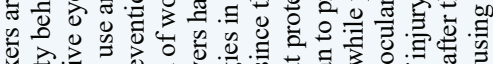

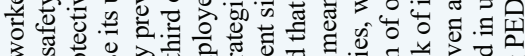

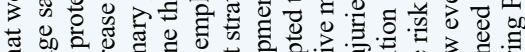

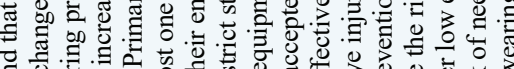

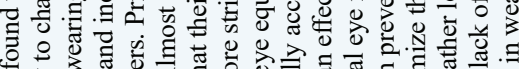

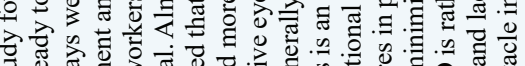

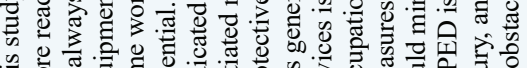

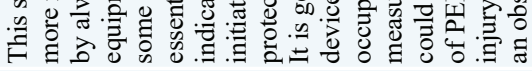

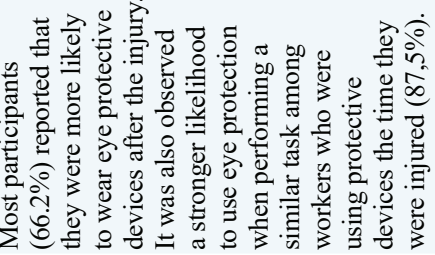
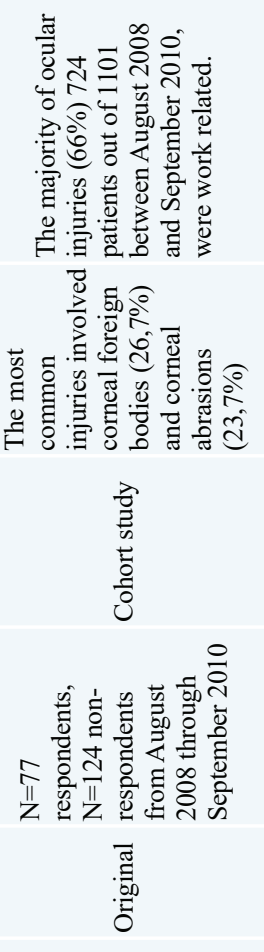

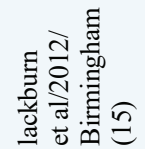
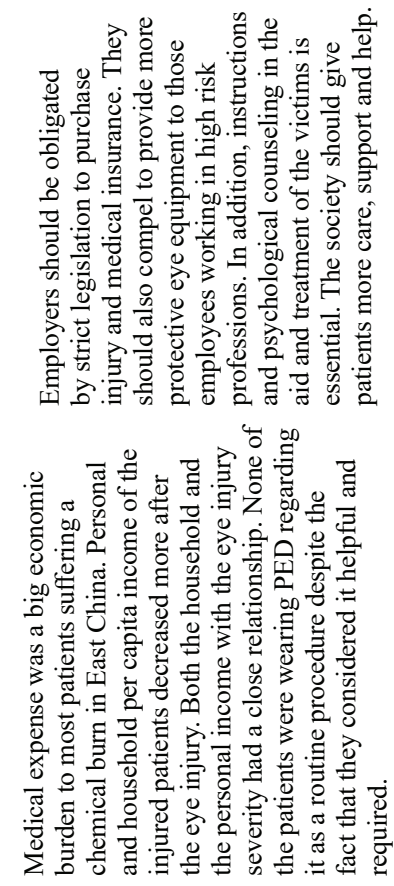

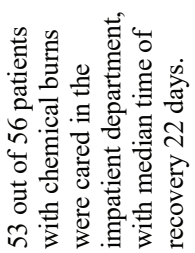
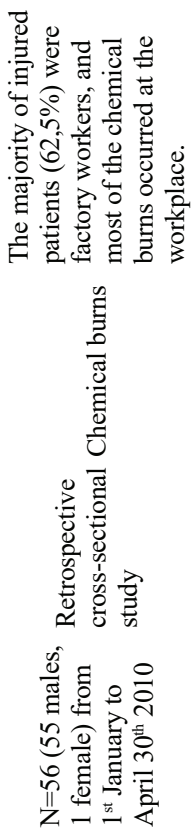

莺

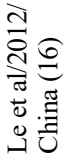

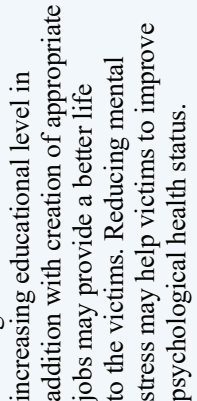

สี ธี
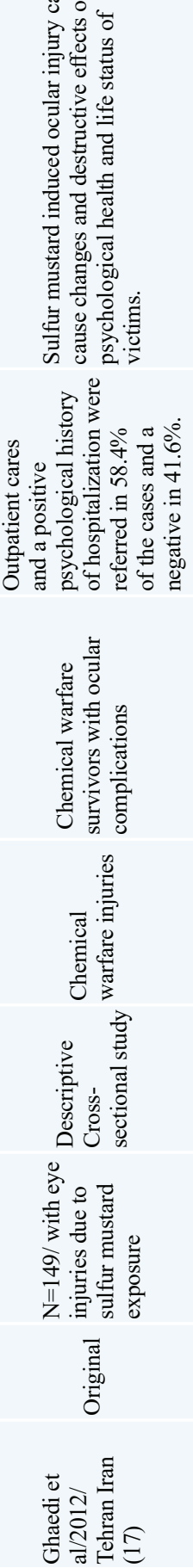

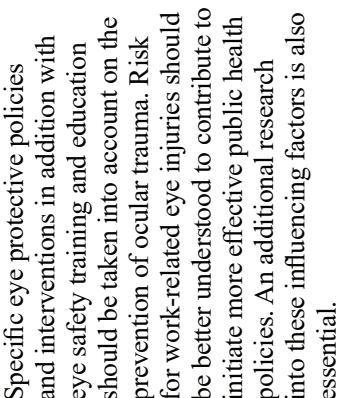

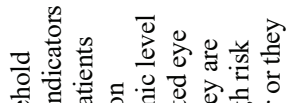

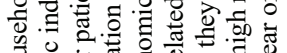

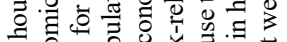

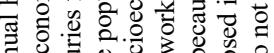

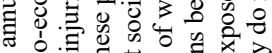
웡 व త 䒠

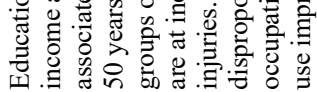

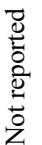

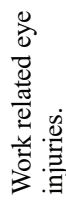

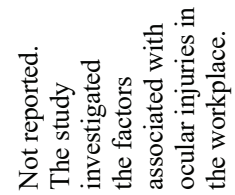

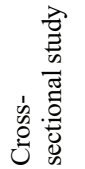

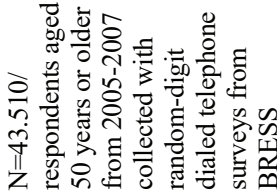<smiles>[CH][CH]</smiles>

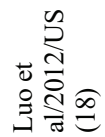



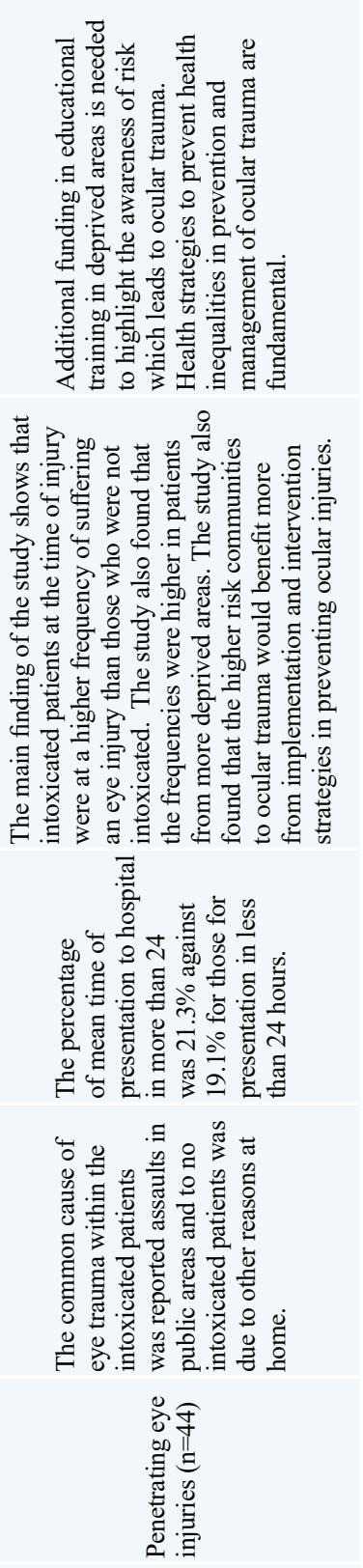

旁旁

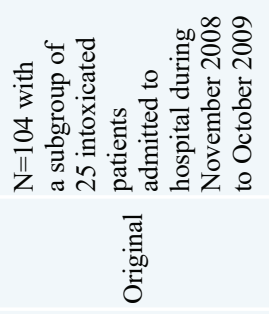

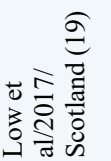

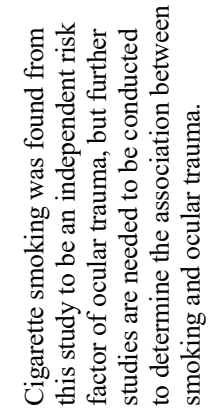

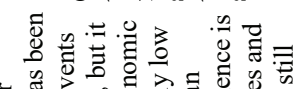

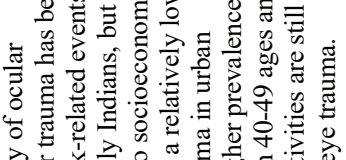

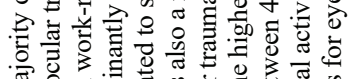

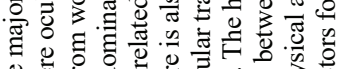
Ð

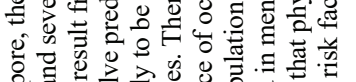

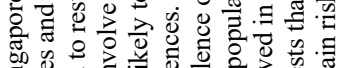

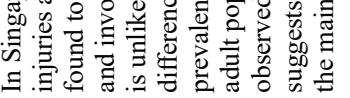
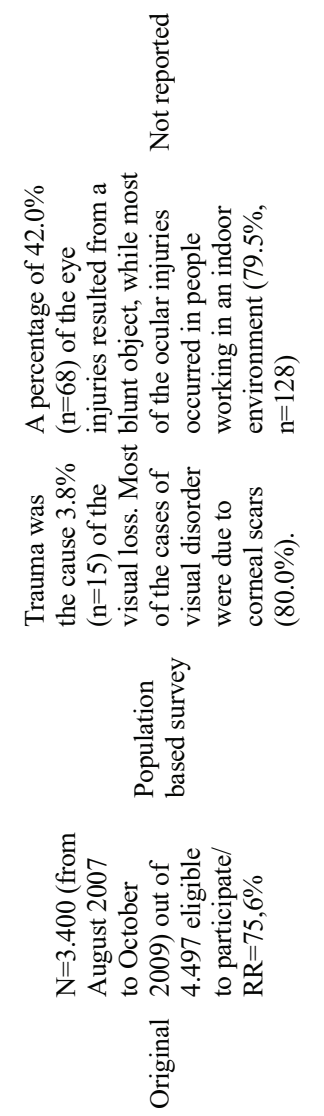

产

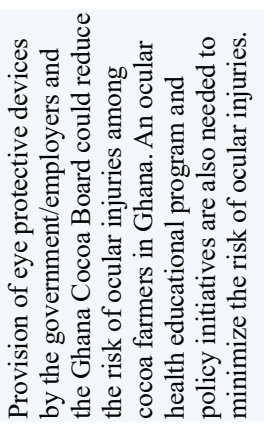

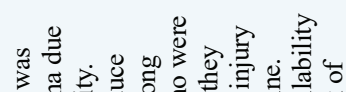

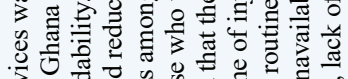

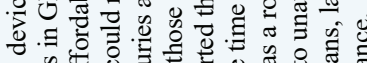

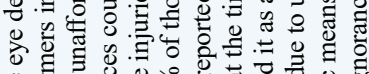

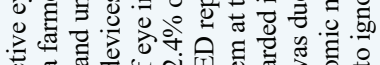

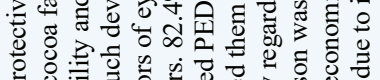

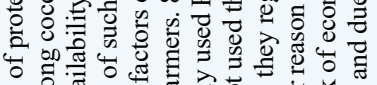

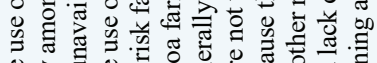

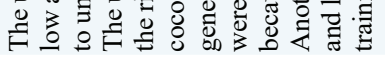

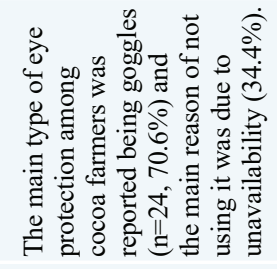

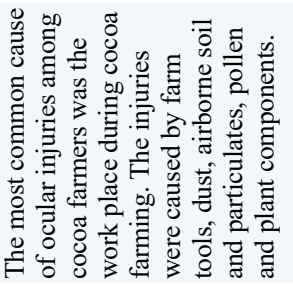
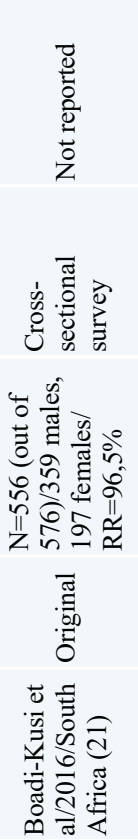

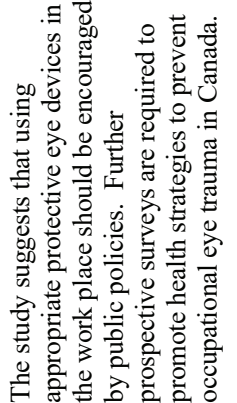

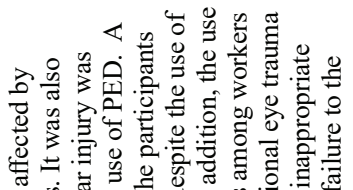

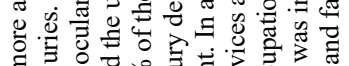

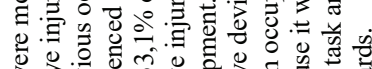

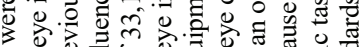

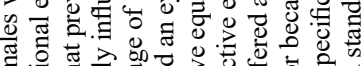

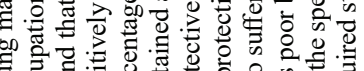

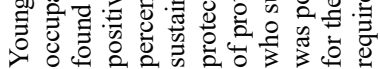
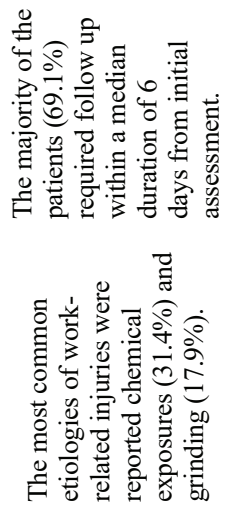

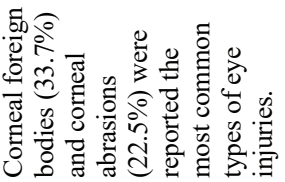
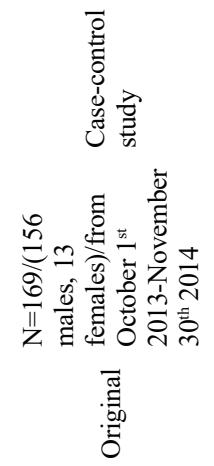

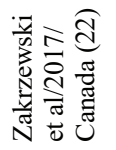



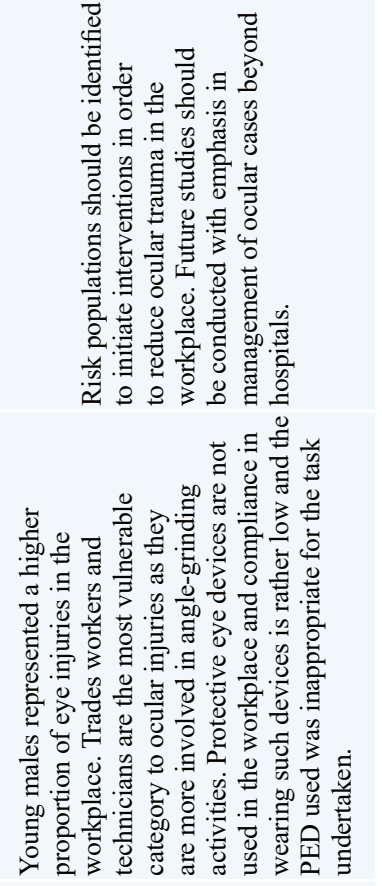

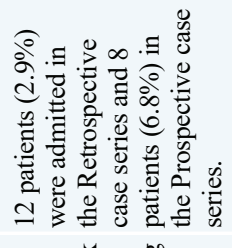

$$
\text { 芦它点 }
$$

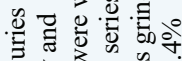

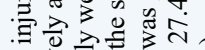

约

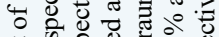

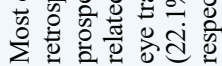

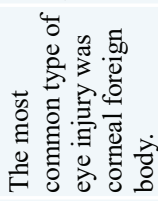

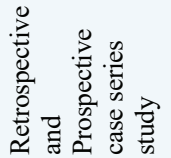

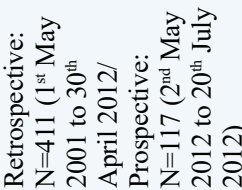

.

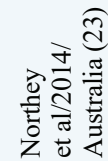
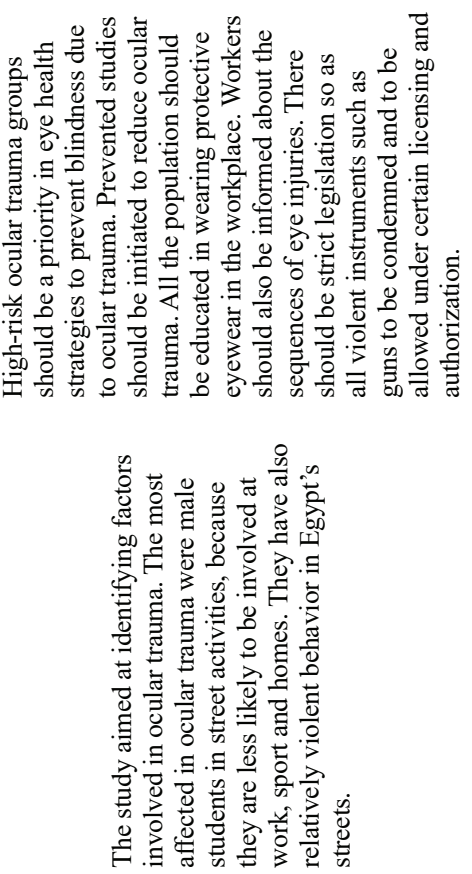

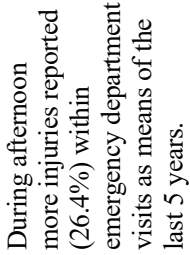

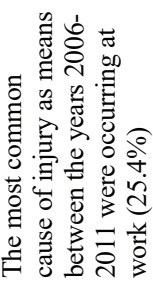

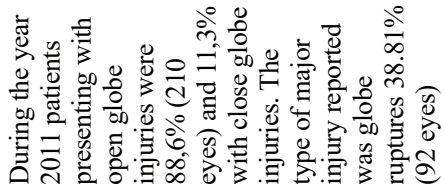

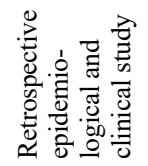

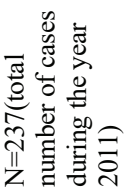

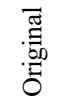

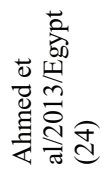

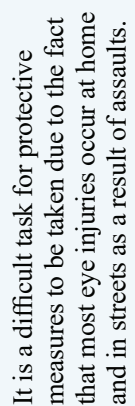

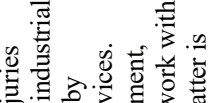

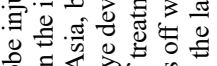

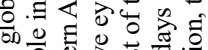

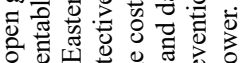

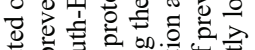

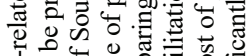

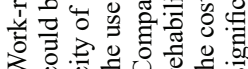

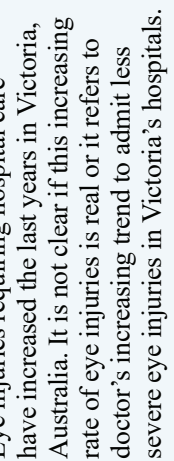

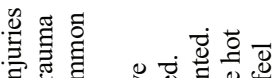

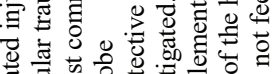

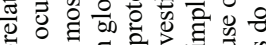

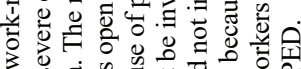

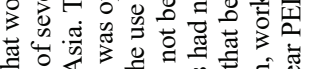
要

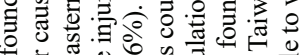

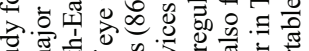

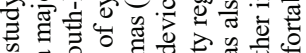
क

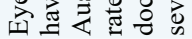

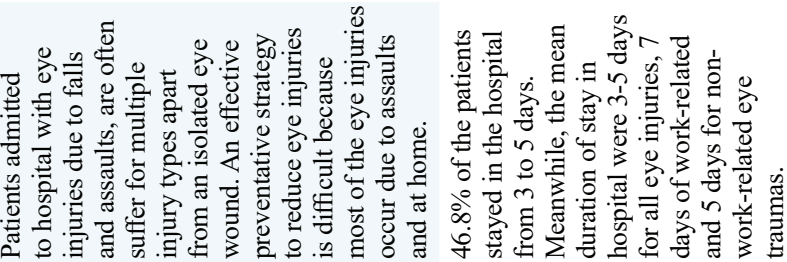
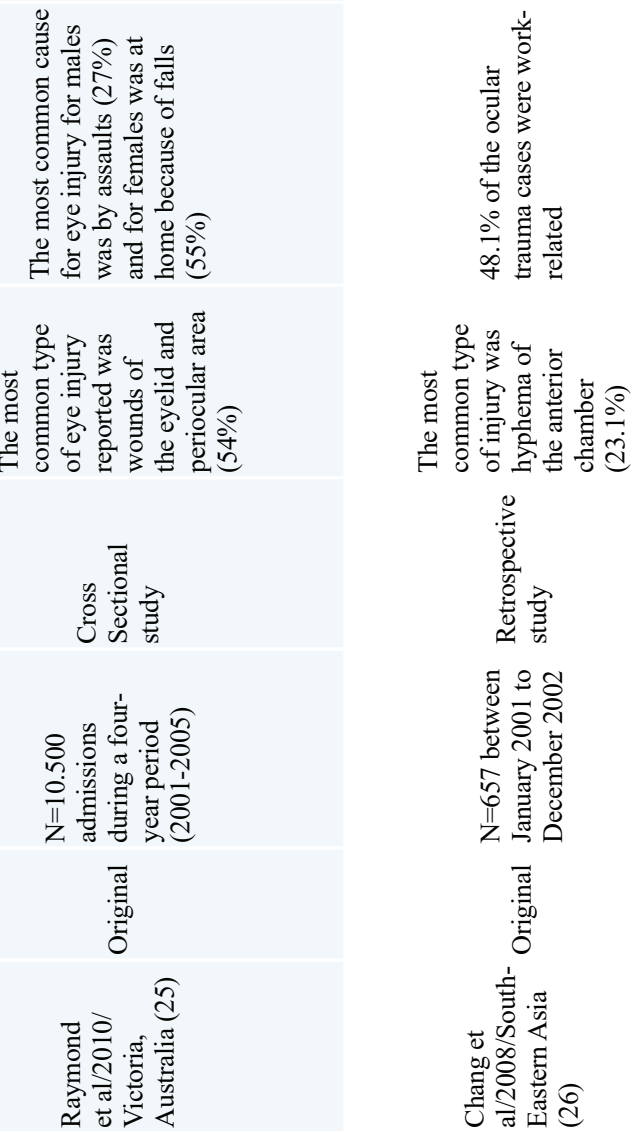


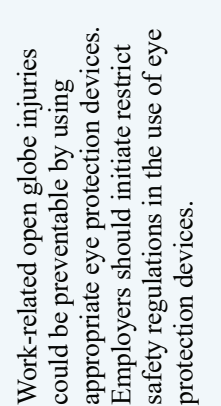

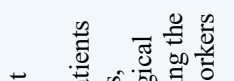

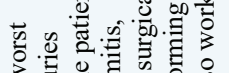
๙ 胥。

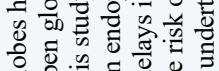

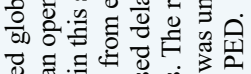

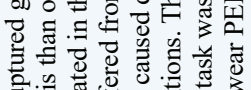

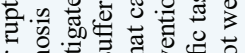

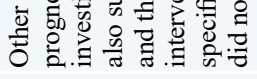

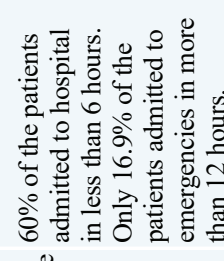

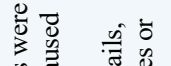

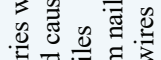

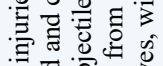

을

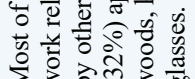

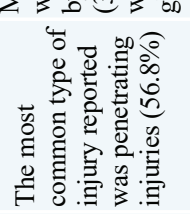

熟高

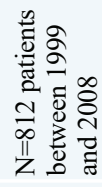

离离

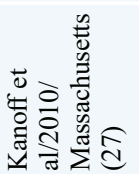

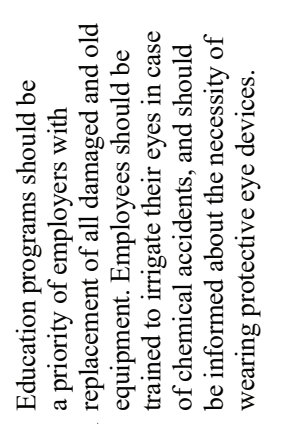

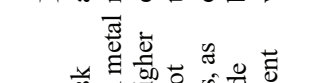

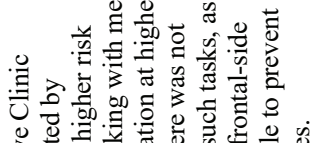

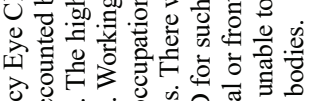

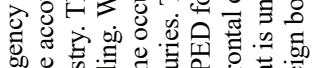

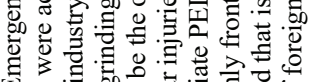

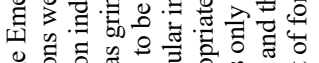

Mn

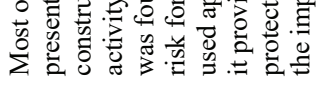
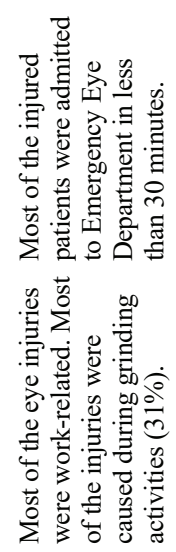

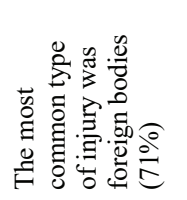

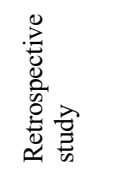

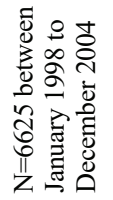
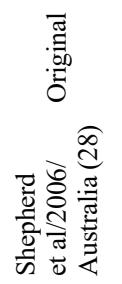

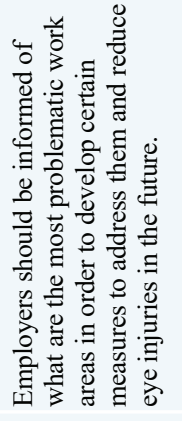

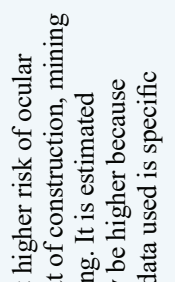

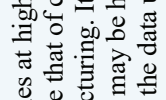

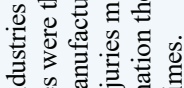

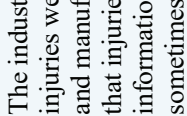

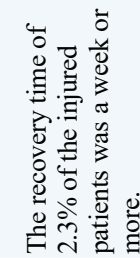

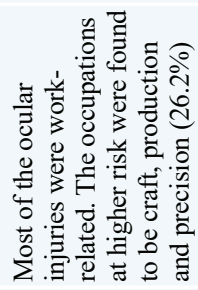

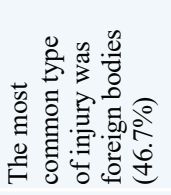
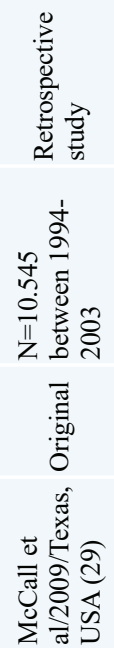

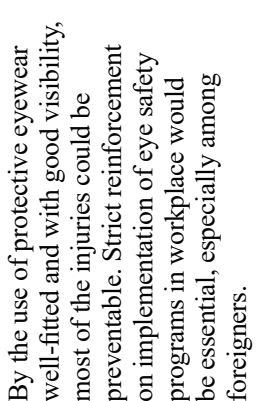

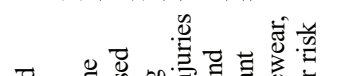

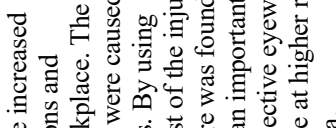

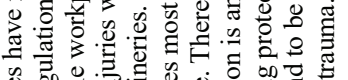

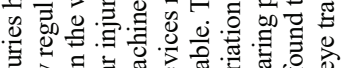

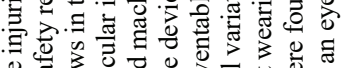

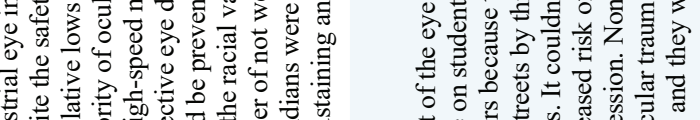

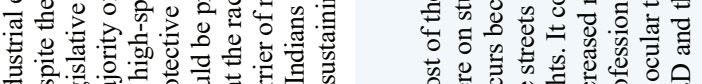

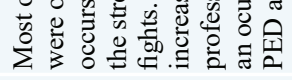

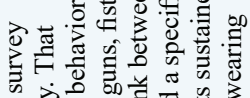

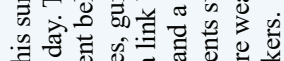

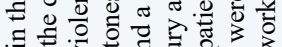

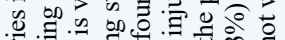

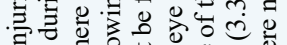

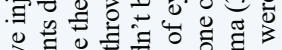

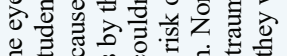
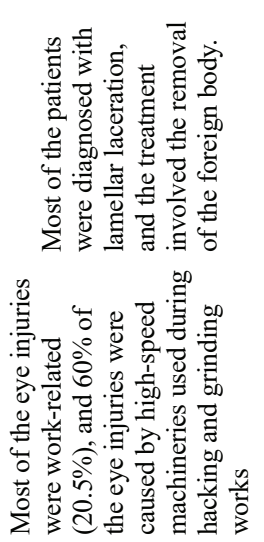

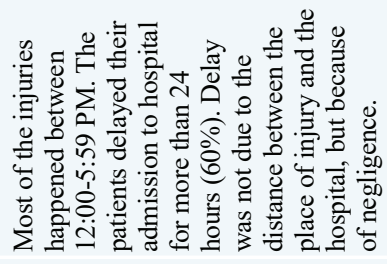

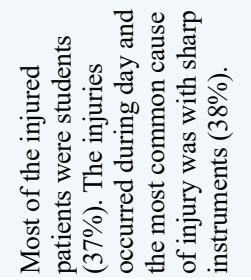

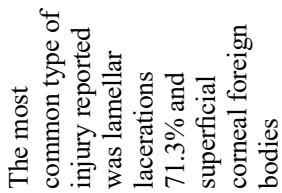

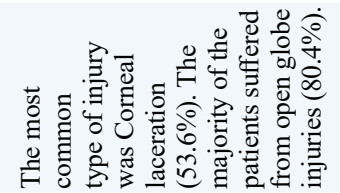
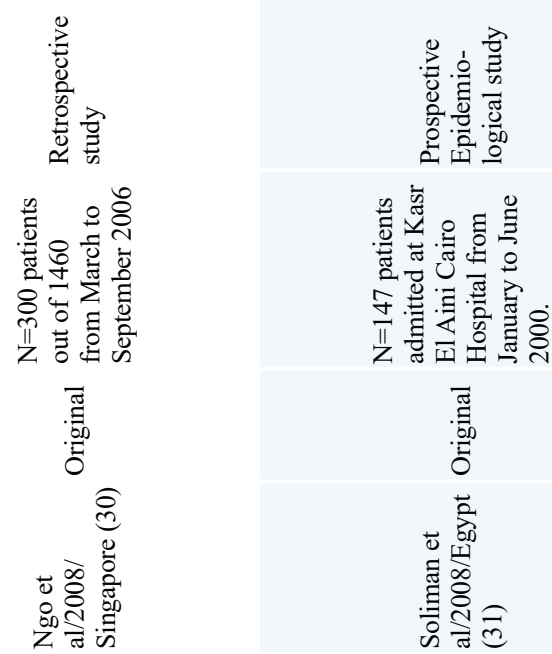
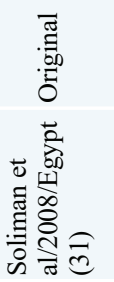


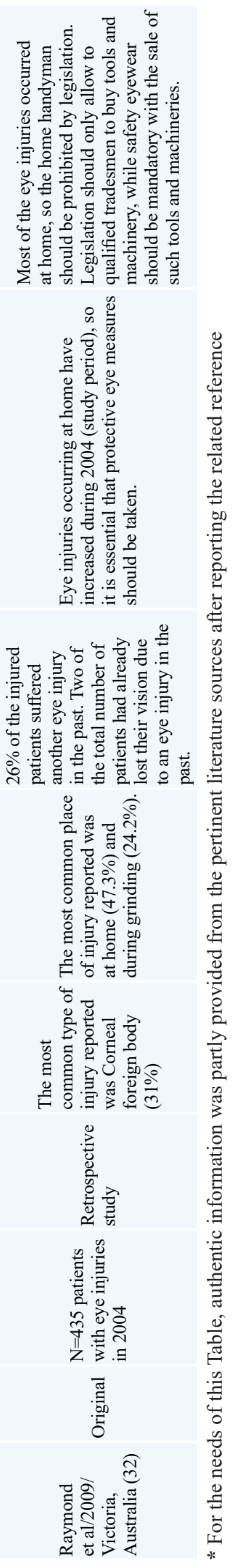

\section{4}

